\title{
К ВОПРОСУ О ПРОДОВОЛЬСТВЕННОЙ ФУНКЦИИ СОВРЕМЕННОГО РОССИЙСКОГО ГОСУДАРСТВА
}

В статье обозначены основные теоретические аспекты обозначения продовольственной функции (функции по обеспечению продовольственной безопасности), как одной из современных функций, присущих Российскому государству. Многообразие направлений современного государственного управления, современные вызовы и глобальные проблемы обуславливают необходимость выделения новых обособленных функций, необходимых для выполнения государством своих социальных обязательств. Самостоятельность продовольственной функции аргументируется автором с учётом её соответствия основным признакам государственной функции, выделяемым в науке: наличия специальных организационно-правовых средств и методов реализации, актуальность для любого этапа исторического развития государства, осознание продовольственной безопасности как самостоятельной сферы публичного управления, а также способность деятельности по обеспечению продовольственной безопасности определять и соответствовать социальному назначению государства В соответствии с международно-правовыми актами, посвящённым вопросам продовольственной безопасности, реализация продовольственной функции должна происходить не только в контексте социального обеспечения, но и путём регулирования агропромышленного комплекса, рынка земли, иных факторов. К целям реализации продовольственной функции Российской Федерации относятся: гарантирование права на питание, входящего в состав конституционного права каждого на достойные условия жизни, реализация публичного интереса (обеспечение продовольственной безопасности как составного элемента национальной безопасности). Высказывается мнение о необходимости принятия единого Федерального закона «О продовольственной безопасности Российской Федерации», в котором будут отражены основные принципы и направления реализации продовольственной функции государства.

Ключевые слова: функции государства, социальное государство, продовольственная безопасность, национальная безопасность, право на достойные условия жизни, право каждого на питание.

A. Mokhov

\section{ON THE FOOD FUNCTION OF THE MODERN RUSSIAN STATE}

The article outlines the main theoretical aspects of the designation of food functions (functions to ensure food security), as one of the modern functions inherent in the Russian state. The variety of directions of modern government, modern challenges and global problems necessitate the allocation of new separate functions necessary for the state to fulfill its social obligations. The independence of the food function is justified by the author with regard to its compliance with the main features of the state function outlined in science: the presence of special organizational and legal means and methods of implementation, relevance to any stage of the state's historical development, awareness of food security as an independent public administration sphere, and food security to determine and comply with the social purpose of the state. In accordance with international legal acts on food security issues, the implementation of the

В условиях современного постиндустриального общества до сих пор актуальными остаются многие «насущные» вопросы, присущие для любого государства - вне зависимости от этапа текущего исторического и экономического развития. Одним из таких вопросов является обеспечение граждан достаточным количеством продовольствия. food function should occur not only in the context of social security, but also by regulating the agro-industrial complex the land market, and other factors. The objectives of the implementation of the food function of the Russian Federation include the guarantee of the right to food, which is part of the constitutional right of everyone to decent living conditions, the realization of public interest (ensuring food security as an integral part of national security). The opinion is expressed on the need to adopt a unified Federal Law "On Food Security of the Russian Federation", which will reflect the basic principles and directions for the implementation of the food function of the state.

Key words: state functions, social state, food security national security, the right to decent living conditions, the right of everyone to food.

Продовольственное снабжение традиционно рассматривается как важнейшая задача государственной власти - причём не только в целях сохранения социально-политической стабильности. Современное государство принимает на себя обязательство по обеспечению, гарантированию и защите целого комплекса прав и свобод личности; значительное место в ряду этих прав зани- 
мают социальные, связанные с необходимостью предоставить каждому (вне зависимости от его государственной принадлежности) базовые условия для достойной и полноценной жизни. Это положение прямо следует из конституционно-правового провозглашения Российской Федерации как социального государства (согласно ст. 7 Конституции РФ 1993 года). Кроме того, защита права на питание регламентируется и на международном уровне. Наиболее полно, отражая современную специфику, оно разъясняется в Изложении фактов Верховного комиссара ООН по правам человека №34 «Право на достаточное питание» (февраль 2011 г.): «Все люди, независимо от их расы, цвета кожи, пола, языка, религии, политических или иных убеждений, национального или социального происхождения, имущественного положения, рождения или иного обстоятельства, имеют право на достаточное питание и право на свободу от голода». Следовательно, продовольствие, его достаточное количество и надлежащее качество, необходимо рассматривать также и как важную гуманитарную ценность.

Особенно важно обеспечить баланс интересов всех нуждающихся в питании (а также ином социальном обеспечении) в условиях постсоветского пространства. Неминуемый переход от тотального административного регулирования экономических процессов к рыночным механизмам может существенно затруднить исполнение государством взятых на себя социальных обязательств. При этом отметим, что действующей Конституцией предусмотрен больший перечень социальных прав по сравнению с Основными законами Советского периода (в частности, добавлено право на коллективную забастовку); кроме того, социальные права предоставлены теперь каждому, а не только гражданину, имеющему соответствующее подтверждение государственной принадлежности. По мнению В.В. Люблинского, ситуация «ослабления социальной политики в связи с экспансией рыночных отношений» может в итоге привести к кризису социального государства, росту напряжённости в обществе [10, с.25].

На наш взгляд, надлежащий уровень питания населения, а также достойные условия и уровень жизни в целом государство сможет обеспечить, только скоординировав все наличные методы и средства в одном определенном направлении т.е., реализуя какую-то свою ффункцию. Таким образом, в целях обеспечения права каждого на питание, а также защиты интересов национальных производителей продуктов питания представляется возможным говорить о наличии продовольственной функции (функции по обеспечению продовольственной безоласности) современного государства.

Заметим, что вопрос о функциях государства традиционно является одним из наиболее разрабатываемых в правовой науке. При этом изучение особенностей государственных функций происходит не только в контексте общетеоретических исследований - напротив, рассмотрение реализации норм отдельных отраслей права зачастую начинается с определения тех функций, при помощи которых государство сможет наиболее эффективно обеспечить надлежащее выполнение нормативных предписаний. Кроме того, активно разрабатываются вопросы о допустимости выделения новых фуннций государства с учётом социально-экономических, политических изменений, а также меняющихся методологических подходов. Так, среди исследований последних лет стоит отметить работы, посвящённые социальной [4], земельной [2], экологической [7], информационной [5] функциям современного государства.

В условиях дифференциации законодательства, возникновения новых отраслей права в качестве самостоятельных, действительно, расширение спектра функций государства представляется обоснованным. Однако, на наш взгляд, нельзя впадать в излишнюю «казуистичность» и выделять функцию только как сугубо теоретическую конструкцию, без надлежащего действительного нормативного и фрактического содержания. Так, например, не совсем обоснованным нам представляется предложение о наличии в качестве обособленной функции землеохранной [16] - которая всё-таки входит в состав экологической (природоохранной) функции государства, самостоятельность которой в контексте современных проблем окружающей среды не вызывает сомнений.

В свою очередь, обоснованность обособления продовольственной функции современного государства необходимо аргументировать через те критерии, которым должна соответствовать любая самостоятельная функция. Наиболее удачной в этой связи нам представляется концепция Л. А. Морозовой, выделяющей такие критерии через способность функции обеспечить и подтвердить социальную сущность государства [15]. Так, к существенным признакам любой функции государства относятся:

1. Наличие устойчивой предметной деятельности государства в сорере предполагаемой функции. На наш взгляд, продовольственное обеспечение можно с полной уверенностью рассматривать как существенную и целенаправленную предметную деятельность государственных органов. Это особенно заметно в контексте формирование системы обеспечения продовольственной безопасности страны. Интересной в этой связи представляется теоретическая позиция о реализации любой новой функции государства через правотворчество, исполнительно-распорядительную и правоохранительную деятельность органов власти в определённой сфере. Так, принятый в 2010 году базовый нормативный акт в области продовольственной политики - Доктрина продовольственной безопасности Российской Федерации (принята Указом Президента РФ от 30.01.2010 №120) - провозглашает целый перечень направлений деятельности по обеспечению и поддержанию состояния продовольственной безопасности страны: социальная, аграрная, фринансовая по- 
литика (в части контроля за ценообразованием), внешнеэкономическая деятельность, стандартизация и контроль качества продуктов. Например, в целях обеспечения социального доступа к продуктам питания (т.е., поддержки наиболее нуждающихся групп населения), в Доктрине указывается на необходимость функционирования общероссийской системы внутренней продовольственной помощи - в целях которой разработана специальная Концепция развития (утверждена Распоряжением Правительства РФ от 3.07.2014 №1215-p). Также указано на организацию питания в учреждениях здравоохранения, образования, социальной сореры (п.11 документа).

2. Связь между рассматриваемой функцией и социальным назначением государства. Целью существования государства является создание нормальных условий для жизни граждан, обеспечение их прав и свобод - которые, согласно положениям ст.2 Конституции, рассматриваются не только как цель публично-властной деятельности, но и как высшая ценность. «Достойная жизнь» и «свободное развитие» человека выделяются Основным законом как главные цели социального государства (ст. 7). Несмотря на то, что необходимость получить необходимое количество продуктов питания прямо не следует из толкования содержания статей Конституции, разъяснения содержания права на достойные условия жизни, данные на международном уровне, позволяют говорить о продовольственной безопасности как о важнейшей предпосылке, «базе» для достижения любым государством своего социального назначения. К примеру, согласно Замечанию общего порядка №12, высказанному по итогам Двадцатой сессии Комитета по экономическим, социальным и культурным прав Экономико-социального совета ООН (апрель - май 1999 г.), право на питание не может толковаться «узко», только как набор определённых питательных веществ. Реализация данного права возможна только в случае, если каждый (коллективно либо самостоятельно) будет иметь достаточные физические и финансовые возможности для получения достаточного питания. Таким образом, обеспечение продовольственной безопасности связано с целым рядом направлений деятельности государств - прежде всего, в социальной и экономической сферах

3. Направленность функции на решение задач государственного управления, характерных для любого этапа исторического развития общества. Потребность в пище является потребностью базовой, поскольку без её удовлетворения невозможно нормальное, здоровое существование человека, его активное участие во всех сферах общественной жизни. Как справедливо замечал один из основоположников теории человеческих потребностей А. Маслоу: «Для человека, который сильно и опасно голоден, не существует других интересов, кроме еды... О таком человеке действительно можно сказать, что он жив хлебом единым» $[12$, с. 58]. По мнению же современных исследователей, человек, ин- стинктивно осознавая необходимость удовлетворения пищевой потребности, активным образом включается в производственные процессы, развивает все остальные сферы общественной жизни $[14$, с. 87$]$

Как представляется, в государственно-правовом плане это связано с необходимостью предоставить человеку возможности для самостоятельного производства продуктов питания (т.е. регулирования сельского хозяйства, использования сельскохозяйственных ресурсов), что также связано с обеспечением права каждого на свободу предпринимательской и иной экономической деятельности. Кроме того, это связано и с обеспечением единого экономического пространства страны, а также защиты прав и имущественных интересов отечественной пищевой промышленности - что особенно актуализировалось в современной обстановке «санкций» и «контрсанкций».

Недостаточность питания не в последнюю очередь связана также и со степенью социальной удовлетворённости населения. Многочисленные исторические примеры показывают нам, что катализатором крупных общественных катаклизмов (бунты, революции, государственные перевороты) зачастую становились именно перебои в снабжении продовольствием - стоит вспомнить Соляной бунт 1648 г., Февральскую революцию 1917 г., активная фаза которой началась с недостатка хлеба в столице, значительный десицит продуктов питания в Советском Союзе второй половины 1980-х гг.

При этом «вечный» характер продовольственной проблемы, её актуальность для любого государства позволяет более пристально обратиться к историческому анализу уже предпринимавшихся мер по обеспечению продовольственной безопасности, определению каких-то типичных кризисных ситуаций и возможных путей их разрешения. Так, например, выделяют непродуманную налоговую политику в сфере АПК, непоследовательность реформ и законодательных нововведений в числе основных причин продовольственной проблемы СССР [6, с.96]. По мнению А. П. Анисимова, основная ответственность за решение продовольственной проблемы ложится на «национальные правительства, нередко подверженные коррупции и неэффективности при принятии решений» [3, с. 9] - что также представляется всегда актуальным вопросом. Поэтому можно с полной уверенностью судить о продовольственной функции как имманентно присущей на всём протяжении существования государства в его современном понимании

4. Наличие определённых форм (прежде все2о, правовых), а также особых методов реализации функции. В связи с обеспечением продовольственной безопасности представляется возможным выделить сразу несколько специфических механизмов реализации: финансово-правовые средства (предоставление дотаций и субсидий местным сельхозтоваропроизводителям, сельскохозяйственное кредитование и стра- 
хование), прямая социальная поддержка (уже упоминавшаяся система внутренней продовольственной помощи), нормативное регулирование в АПК, применение мер ответственности за нарушение требований в сельском хозяйстве (прежде всего, экологических и требований качества и безопасности пищевой продукции). Специальной (за исключением Конституции, а также положений международного права) правовой основой для их функционирования выступает Доктрина продовольственной безопасности, а также целый комплекс актов федерального и регионального уровня (принятых во исполнение Доктрины или продолжающих своё действие и после её принятия). Как справедливо отмечает в своей статье В. В. Кожевников, на сегодняшний день продовольственная безопасность «охватывает широкий спектр национальных, экономических социальных, демографических и экологических фракторов» [9, с. 60]. В связи с этим мы не совсем согласны с С. С. Симоновой, рассматривающей обеспечение продовольственной безопасности только как одно из направлений социальной функции современного государства [17] - на сегодняшний день продовольственная проблема намного шире. Так, одним из значительных направлений современной международной системы продовольственной безопасности является решение проблем климата - и связанных с ними проблем сокращения плодородия почв, площадей пастбищ, пригодных для аквакультуры естественных водных объектов

Обозначая соответствие продовольственной функции государства четырём вышеуказанным критериям, необходимо также, на наш взгляд, выделить ещё одно важное условие, позволяющее существовать функции в качестве самостоятельной - наличие публичного интереса в том благе, на обеспечение которого направлена та или иная функция. Несомненно, приоритет прав и свобод личности не подвергается здесь сомнению. Однако, рассматривая продовольственную безопасность как значительную и важную составляющую безопасности национальной, нельзя не иметь в виду, что она, в свою очередь, рассматривается законодателем как "состояние защищённости личности, общества, и государства" (ст. 6 Стратегии национальной безопасности Российской Федерации; утв. Указом Президента РФ от 31.12.2015 г. № 683); следовательно, необходим и учёт интересов государства, сохранения государственного суверенитета

Наличие особых государственных и общественных интересов, превалирующих над интересами отдельно взятого лица (гражданина или организации) наиболее ярко проявляется в реализации норм о специальных экономических мерах, связанных с запретом ввоза на территорию РФ пищевой продукции, произведённой в некоторых странах. При этом государство использует определённые «сдержки», не делая такой запрет универсальным и безоговорочным. Так, Верховным Судом РФ в 2015 г. было признано необосно- ванным изъятие у прибывающих на территорию РФ туристов продуктов, приобретённые ими с целью личного потребления: «Введённые меры не должны затрагивать прав граждан на ввоз запрещенной продукции в личных целях) (Определение Верховного Суда РФ от 11.11.2015 г. по делу № АКПИ15-1007). Как отмечает по поводу данного решения высшей судебной инстанции Д. И. Игнатов: «Такая позиция обеспечивает баланс интересов личности и государства, указывает на публичный характер установленных специальных экономических мер и границы их влияния на частные интересы граждан как потребителей» $[8$, c. 222].

Особенно важным это представляется при наличии в теории конструкции «продовольственного суверенитета», который представляет собой высокую степень локализации производителей пищевой продукции, с последующим достижением продовольственной независимости (полностью или в подавляющей части) по ключевым продуктам питания. При этом достижение автаркии не может рассматриваться как цель продовольственного суверенитета; в условиях повышения разнообразия рациона питания полностью заместить все необходимые продукты отечественными невозможно даже для такой большой по территории и аграрно-климатическим условиям страны, как Российская Федерация. В этой связи представляется верным мнение А. В. Малова, согласно которому «продовольственная безопасность - это «цель» государства (в том числе, и соответствующей продовольственной функции), а суверенитет - это «стратегия» (план действий) по её достижению» $[11$, с. 240]. Таким образом, определённый национальный интерес также выступает как фактор, позволяющий говорить об актуальности обеспечения продовольственной безопасности страны, её институциональном единстве в пределах самостоятельной функции.

Кроме собственно “управленческого» интереса, достаточно важным нам представляется научный интерес, предъявляемый в последние годы к категории «продовольственная безопасность». Доктриной прямо обозначается развитие научного потенциала аграрных исследований, исследований в области качества и безопасности питания. Развитие научного потенциала АПК одна из задач повышения производственного потенциала отрасти в целом (п. 13 документа) При этом правовым исследованиям необходимо уделять повышенное внимание. А. И. Мелихов, Г. А. Никитина и Г. С. Працко на основе проведённого анализа вышедших в последние годы диссертационных работ по вопросам безопасности (в том числе, и продовольственной) указывают на существенный «крен» исследований в сторону политических и экономических вопросов, что, на взгляд учёных, свидетельствует об однобоком рассмотрении проблемы, не предлагающим при этом её комплексного разрешения $[13$, с. 187] Несмотря на то, что продовольственная безопасность определена в Доктрине как «состояние на- 
циональной экономики», основой функционирования национальной системы продовольственной безопасности, соответствующей публично-властной деятельности выступает именно нормативный материал. Поэтому, как представляется, обособление продовольственной функции имеет также и большое теоретическое значение, служа своеобразным стимулом для дальнейших научно-правовых исследований, способных выработать конкретные практические предложения.

Исходя из всего вышеизложенного, под продовольственной функцией современного государства предлагается понимать самостоятельное, связанное с решением задачи и преодолением проблем современного этапа развития государства направление публично-властной деятельности, направленной на обеспечение продовольственной безопасности страны, гарантирования и защиты права каждого на питание, выполнение иных, прямо не связанных с продовольственной безопасностью, требований (экономических, социальных, экологических и т.д.), направленных на предоставление каждому достаточного для нормальной экономически активной жизни количества продовольствия.

Продовольственная функция является самостоятельной для Российского государства, поскольку соответствующая обеспечительная деятельность носит постоянный характер, продовольственная безопасность имеет непосредственную связь с реализацией государством своего социального назначения; в современных условиях продовольствие необходимо рассматривать как важный публичный интерес, предпосылку для обеспечения государственного суверенитета. Продовольственная функция имеет свои специфические формы и способы реализации (прежде всего, правовые), однако до сих пор не существует единого федерального нормативного акта, закрепляющего общие принципы обеспечения национальной продовольственной безопасности. Поскольку Доктрина продовольственной безопасности РФ не носит нормативного характера, принятие в ближайшей перспективе Федерального закона «О продовольственной безопасности Российской Федерации» не только унифицирует уже существующие подзаконные акты в данной сфере, приведёт к единообразию действующие в субъектах РФ самостоятельные законы о продовольственной безопасности, принятые, по меткому замечанию А. П. Анисимова, в порядке «опережающего нормотворчества" [1, c. 66], разрешит имеющиеся терминологические проблемы и компетенционные коллизии.

\section{Литература}

1. Анисимов А. П. Законодательство субъектов РФ в области обеспечения продовольственной безопасности: сравнительно-правовое исследование // Научный вестник Волгоградского филиала РАНХиГС. Серия: Юриспруденция. 2019. T.5. №1. С. $64-71$.

2. Анисимов А. П., Рыженков А. Я. Земельная функция современного государства: монография. М.: Новый индекс, 2012. $192 \mathrm{C}$

3. Анисимов А. П. О некоторых теоретических проблемах обеспечения продовольственной безопасности России // Правовые институты и методы охраны окружающей среды в России, странах СНГ и Европейского Союза: законодательство и экологическая эффективность. Сборник научных статей $\vee$ Международной научно-практической конференции преподавателей, практических сотрудников, студентов, магистрантов, аспирантов (г. Саратов, 5 октября 2018 г.). Саратов: СГУ, 2018. С. 7-10

4. Аристов Е. В. Социальность государства: зарубежный опыт конституционно-правового обеспечения: дис. ... доктора юрид. наук. Пермь, 2017. 474 с.

5. Васенина А. Н. Информационная функция современного российского государства: дис. ... канд. юрид. наук Нижний Новгород, 2007. 217 с

6. Власов В. А., Насада А. Ю. Правовое регулирование обеспечения продовольственной безопасности населения СССР в период с 1930 года по 1990 год: историко-правовой анализ // Аграрное и земельное право. 2019. №1. С. 92-97.

7. Гиззатуллин Р. Х. Экологическая функция государства: теория и практика реализации: дис. ... доктора юрид. наук. М., 2014. 442 c.

8. Игнатов Д. А. Меры по обеспечению экономической безопасности в судебных актах Верховного Суда Российской Федерации // «Пробелы) в Российском законодательстве. 2016. №5. С. 220-222.

9. Кожевников В. В. Обеспечение государственной продовольственной безопасности как средство предупреждения риска ущемления его суверенитета // Аграрное и земельное право. 2018. №7. С. 46-62.

10. Люблинский В. В. Социальное государство: трудная адаптация в условиях меняющегося миропорядка // Власть. 2017. №8. C. 24-33.

11. Малов А. В. Продовольственный суверенитет: политическая концепция, общественное движение и контр-гегемонистский дискурс XXI века // Государственное управление: электронный вестник. 2017. №65. С. 221-246.

12. Маслоу А. Мотивация и личность. СПб.: Издательство «ПИТЕР», 2019. 400 с.

13. Мелихов А. И., Никитина Г. А., Працко Г. С. Понятие «безопасность» в современных гуманитарных науках и законодательстве России // Научный вестник Волгоградской академии МВД России. 2019. №2. С. 183-188.

14. Момджян К. Х. К типологии человеческих потребностей // Вестник Московского государственного университета. Серия 7. Философия. 2015. №4. С. 78-94.

15. Морозова Л. А. Функции российского государства на современном этапе // Государство и право. 1993. №6. С. 98108

16. Саакян А. В. Новая функция современного государства: вопросы теории и практика // Современное право 2009. №7. C. 15-18. 
17. Симонова С. С. Социальная функция государства по обеспечению продовольственной безопасности // Бизнес образование. Право. Вестник Волгоградского института бизнеса. 2014. №2. С. 277-279.

\section{References}

1. Anisimov A. P. Zakonodatel'stvo subs)ektov RF v oblasti obespecheniya prodovol'stvennoi bezopasnosti: sravnitel'nopravovoe issledovanie (Legislation of the constituent entities of the Russian Federation in the field of food safety: comparative legal research) // Nauchnyi vestnik Volgogradskogo filiala RANKhiGS. Seriya: Yurisprudentsiya. 2019. T.5. No.1. P. 64-71. (In Russian)

2. Anisimov A. P., Ryzhenkov A. Ya. Zemel'naya funktsiya sovremennogo gosudarstva: monografiya (Land function of the modern state: monograph). M.: Novyi indeks, 2012. 192 p. (In Russian).

3. Anisimov A. P. O nekotorykh teoreticheskikh problemakh obespecheniya prodovol'stvennoi bezopasnosti Rossii (On some theoretical problems of ensuring food security of Russia) // Pravovye instituty i metody okhrany okruzhayushchei sredy v Rossii, stranakh SNG i Evropeiskogo Soyuza: zakonodatel'stvo i ekologicheskaya effektivnost'. Sbornik nauchnykh statei $\checkmark$ Mezhdunarodnoi nauchno-prakticheskoi konferentsii prepodavatelei, prakticheskikh sotrudnikov, studentov, magistrantov, aspirantov (g. Saratov, 5 oktyabrya 2018 g.). P. 7-10. (In Russian).

4. Aristov E. V. Sotsial'nost' gosudarstva: zarubezhnyi opyt konstitutsionno-pravovogo obespecheniya. (The sociality of the state: foreign experience of constitutional and legal support); thesis. Perm', 2017. 474 p. (In Russian).

5. Vasenina A. N. Informatsionnaya funktsiya sovremennogo rossiiskogo gosudarstva. (Information function of the modern Russian state): thesis. Nizhnii Novgorod, 2007. 217 p. (In Russian)

6. Vlasov V. A., Nasada A. Yu. Pravovoe regulirovanie obespecheniya prodovol'stvennoi bezopasnosti naseleniya SSSR v period s 1930 goda po 1990 god: istoriko-pravovoi analiz (Legal regulation of food security of the population of the USSR in the period from 1930 to 1990: historical and legal analysis) // Agrarnoe i zemel'noe pravo. 2019. No 1. P. 92-97. (In Russian)

7. Gizzatullin R. Kh. Ekologicheskaya funktsiya gosudarstva: teoriya i praktika realizatsii (Ecological function of the state: theory and practice of implementation): thesis. Moscow, 2014. 442 p. (In Russian).

8. Ignatov D. A. Mery po obespecheniyu ekonomicheskoi bezopasnosti v sudebnykh aktakh Verkhovnogo Suda Rossiiskoi Federatsii (Measures to ensure economic security in judicial acts of the Supreme Court of the Russian Federation) // "Probely» v Rossiiskom zakonodatel'stve. 2016. No 5. P. 220-222. (In Russian).

9. Kozhevnikov V. V. Obespechenie gosudarstvennoi prodovol'stvennoi bezopasnosti kak sredstvo preduprezhdeniya riska ushchemleniya ego suvereniteta (Ensuring state food security as a means of preventing the risk of infringement of its sovereignty) // Agrarnoe i zemel'noe pravo. 2018. No 7. P. 46-62. (In Russian).

10. Lyublinskii V. V. Sotsial'noe gosudarstvo: trudnaya adaptatsiya $v$ usloviyakh menyayushchegosya miroporyadka (The welfare state: difficult adaptation in a changing world order) // Vlast'. 2017. No 8. P. 24-33. (In Russian).

11. Malov A. V. Prodovol'stvennyi suverenitet: politicheskaya kontseptsiya, obshchestvennoe dvizhenie i kontrgegemonistskii diskurs XXI veka (Food Sovereignty: Political Concept, Social Movement and Counter-Hegemonic Discourse of the 19th Century) // Gosudarstvennoe upravlenie: elektronnyi vestnik. 2017. No 65. P. 221-246. (In Russian).

12. Maslou A. Motivatsiya i lichnost'. (Motivation and personality). St.Petersburg: PITER publ., 2019. 400 p. (In Russian)

13. Melikhov A. I., Nikitina G. A., Pratsko G. S. Ponyatie «bezopasnost'» v sovremennykh gumanitarnykh naukakh i zakonodatel'stve Rossii (The concept of "security» in modern humanities and Russian legislation) /" Nauchnyi vestnik Volgogradskoi akademii MVD Rossii. 2019. No 2. P. 183-188. (In Russian).

14. Momdzhyan K. Kh. K tipologii chelovecheskikh potrebnostei (On the typology of human needs) // Vestnik Moskovskogo gosudarstvennogo universiteta. Seriya 7. Filosofiya. 2015. No 4. P. 78-94. (In Russian).

15. Morozova L. A. Funktsii rossiiskogo gosudarstva na sovremennom etape (Functions of the Russian state at the modern stage) // Gosudarstvo i pravo. 1993. No 6. P. 98-108. (In Russian).

16. Saakyan A. V. Novaya funktsiya sovremennogo gosudarstva: voprosy teorii i praktika (The new function of the modern state: theory and practice) // Sovremennoe pravo. 2009. No 7. P. 15-18. (In Russian).

17. Simonova S. S. Sotsial'naya funktsiya gosudarstva po obespecheniyu prodovol'stvennoi bezopasnosti (The social function of the state to ensure food security) // Biznes. Obrazovanie. Pravo. Vestnik Volgogradskogo instituta biznesa. 2014. No 2. P. 277-279. (In Russian).

\section{Сведения об авторе}

Мохов Артем Юрьевич - ассистент кафедры конституционного и административного права Волгоградского института управления РАНХиГС (Волгоград) / aumohov@mail.ru

\section{Information about the author}

Mokhov Artem - assistant, Chair of of Constitutional and Administrative Law, Volgograd Institute of Management - Branch of the RANEPA (Volgograd) / aumohov@mail.ru 